\title{
Knowledge, attitude and practice of mothers with children less than five years toward vaccination in khartoum state- ummbada locality-allbugaa- 2017
}

\author{
Khalid Haroon Fad*, Alshafee Adam Ibrahim, Mastora Mohammed BaharDldoom and Zienab Osman Hassan Ahmed \\ Department of Health Education College of Public \& Environmental Health, University of Bahri Sudan
}

\begin{abstract}
The knowledge of the mothers on immunization - a public health intervention that has greatly reduced mortality and morbidity globally- is very vital as they play a great role in child care. Their ability to have the right knowledge will enhance their practice and attitude toward immunization. This cross- sectional descriptive study was conducted in Khartoum State Ummbada locality (Albugaa) in period from 5th February to 6th March-2017. Aimed to study the knowledge, attitudes and practice of mothers with children under five years toward vaccination, the study was included 384 mother which have children under five years, divided into six area. The data was collected through questionnaire and interview, and data was analyzed by handily an excel program. The study shown that the majority $90 \%$ of mothers heard about the hear of vaccination, about $52 \%$ of mothers had poor knowledge about number of the routine doses which given to the child less than two years, $55 \%$ of mother had negative attitudes toward vaccination of child in vaccination campaigns, and $66 \%$ of mothers good practice toward their treated with the side effects of vaccines. We recommended to Ministry of Health of Khartoum State should be conducting health education campaigns about vaccination for mothers continuously through media and Provided mothers with vaccination booklets explain the importance of vaccination, routine doses, importance of vaccination card and how to manage the side effects of vaccination, and obligating all health centers to provided health instructions about vaccination for mothers.
\end{abstract}

\section{Introduction}

The World Health Organization (WHO) has defined immunization as the process whereby a person is made immune or resistant to an infectious disease, typically by the administration of a vaccine. These vaccines help to stimulate the body's own immune system to protect the person against subsequent infection or disease [1].

Immunization therefore depicts the ability to develop immunity. Immunity being the state of having sufficient biological defenses to avoid infection, disease, or other unwanted biological invasion [2]. Immunity also depicts the capability of the body to resist harmful microbes from gaining access into it.

Vaccination is one of the most cost-effective interventions to prevent major illnesses that contribute to child mortality in the country, particularly in environments where malnourished children, overcrowding, poverty and illiteracy reign. Knowledge (K), positive attitudes (A) and appropriate perceptions $(\mathrm{P})$ about vaccination hence become one of the main tools to reduce the incidence of vaccine preventable diseases (VPDs) thus reducing childhood mortality and morbidity. In our society, a large chunk of the population lives in rural areas, where mothers are illiterate and have numerous myths about vaccination; this results in children being unimmunized and susceptible and hence causes a serious policy concern. Evidence about the inequalities in vaccination practices exist even though childhood immunization has been an important part of maternal and child health services since the 1940 [3].

In 2010 it was estimated that 1.7 million children died from vaccine preventable diseases [4]. It was also noted that 19.3 million children had been incompletely vaccinated, leaving them susceptible to vaccine preventable disease mortality and morbidity. Approximately $50 \%$ of all under vaccinated children live in three countries, India being one of them.

\section{Justification of study}

Immunization which has greatly reduced the burden of infectious disease ؛ prevent illness 'disabilities and death frames the vaccine preventable disease including: Measles, Pertussis, Diphtheria, ، Rubella ' polio ‘ and Tetanus [5].

Immunization child significantly reduce cost of treating disease ، thus providing healthy childhood and reducing poverty and suffering [6].

More than 720,000 under one-year children in Sudan will this year be vaccinated against meningitis through the routine immunization system

A mini catch-up campaign will be conducted in September 2016 targeting 5.2 million 1_5 years' old children born after the mass meningitis vaccination campaign carried out in 2012_2013 to further reduce the threat of meningitis in Sudan. (FMOH, 2012).

${ }^{\star}$ Correspondence to: Khalid Haroon Fad, Department of Health Education College of Public\& Environmental Health, University of Bahri Sudan, E-mail: khalidharoon25@yahoo.com

Key words: mothers, vaccination, awareness

Received: May 31, 2019; Accepted: June 20, 2019; Published: June 27, 2019 


\section{Objectives of the study}

General objective: To study the Knowledge Attitude and Practices (KAP) of Mother which have children under five years toward Vaccination children Ummmbada locality.

Specific objective: To identify Knowledge of mothers about the vaccination of children under five years.

To investigate attitudes of mothers with child in vaccine preventive disease.

To know the practices of mothers about vaccination of children under five years.

\section{Materials and methods}

\section{Study design}

This is descriptive cross-sectional study, aimed to study of Knowledge Attitude and practice of mothers which have children under five years toward vaccination.

\section{Study area}

Khartoum is the capital of Sudan and it is one of the (18) State of Sudan. Consist of 7 localities, (al-Khartoum locality, al- Khartoum Bahri locality, Omdurman locality, JabalAwliya locality, Sharq annil locality, Ummmbadda locality and Karari locality). Its area is $(22.142 \mathrm{~km})$ ' and population $(5,274,321$ in 2008 census).It is lies between longitudes 31.5 to $34 \mathrm{E}$ and latitudes 15 to $16 \mathrm{~N}$.the River Nile is divided Khartoum State in the three part, Khartoum locality, Khartoum Bahri locality and Omdurman locality and its neighbor with River Nile state in the north _ east, in the north- west by the Northern State, in the east and south east by the state of Kassala, Gadaref and Gezira and in the west by North Kurdofan. The city is located in the middle of Sudan at the confluence of the White Nile and the Blue Nile, where the two rivers unite to form the River Nile.

Omdurman is the largest city in Sudan and Khartoum State lying on the western bank of the River Nile .opposite in capital Khartoum Omdurman has population of 2.395.195(2008) and the national center of commerce with Khartoum and Bahri.

\section{Study population}

The target population consist of mothers have children under five years in study area.

\section{Sample Size}

According to the total number of population in albugaa health district 384 using this formula

$$
\begin{aligned}
& \mathrm{n}=\mathrm{Z}^{2} \mathrm{Pq} \\
& \mathrm{n} \mathrm{e}^{2} \\
& \mathrm{z} \text { : the sample size. } \\
& \mathrm{p} \text { : the estimation not available then } \mathrm{p}=(50 \%) \\
& \mathrm{q}: 1-\mathrm{p} \\
& \mathrm{e}: \text { marginal error equal }(0.05) \\
& \mathrm{n}=(1.96)^{2} \times 50 \times 50=384
\end{aligned}
$$

\section{The sample distribution techniques}

The sample selection divided into six areas, the first house was selected by random sample distribution technique and the second house was selected by add interval and applying this method into all study area.

\section{Data collection}

Questionnaire: The questionnaire was designed by researchers to purpose of obtain information about knowledge, attitude and practice of mothers which have children less than five years toward vaccination

Interviews: The interview was designed by researchers to obtain information about vaccination from staff of the Ministry of health of Khartoum State and Ummbada locality information face to faceannex, no (2).

Data analysis: Data was analyzed by handily an excel program present figures and tables.

\section{Discussion}

The result shown that most mothers have children less than five years their age between $18-25$ (42\%) see in Figure 1. This result agrees with the study done in Almygoma health center by Butal Hassan Mohammed, 2013 which proved that the age of mothers less than 25year (44\%).

The result shown that the most mothers education level was basis school (30\%) see in Figure 2, this education level of mothers can affected on their knowledge which reflecting in their attitudes and practice and this result agree with the study done in Alkalakla by Eman Ali which shown that less than half of mothers (41\%) was basis

The result revealed that $39 \%$ of families belonged to income level from 500-1000SD see in Table 1, this can affected on the transportation to going to the health center for receiving the vaccination doses and may be reason for mothers to not vaccinate their children at specified time of vaccination.

The result revealed that the majority of mothers (90\%) heard about vaccination see in Figure 3, this result similar to study done in India by Mrs. Sujathan in 2007 that shown $86 \%$ of mothers heard of immunization.

The result revealed the mothers excellent knowledge about importance of vaccination which it is protect from diseases and

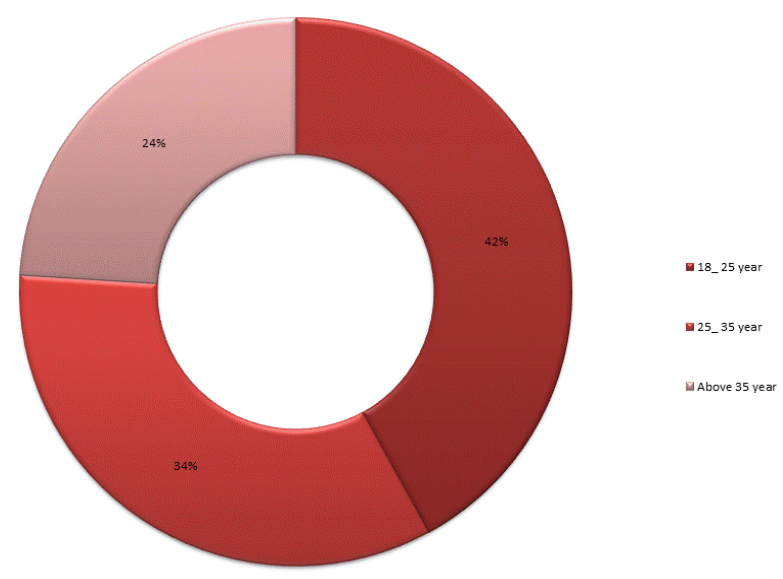

Figure 1. Show the mothers according to age _ Ummbada locality _Albugaa $2017 \mathrm{n}=384$ 


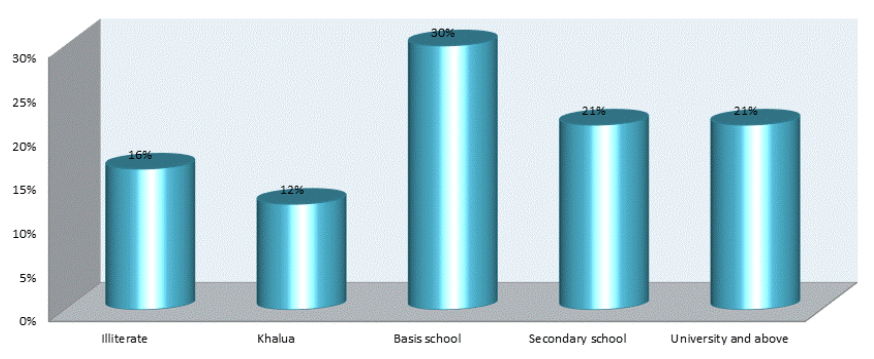

Figure 2. Show the education level of mother's children_Ummbada locality_Albugaa $2017 \mathrm{n}=384$

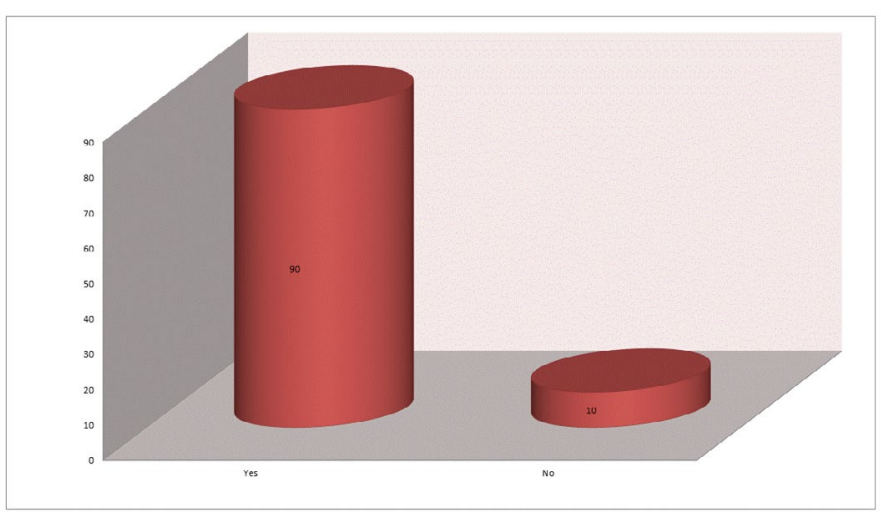

Figure 3. Show the mothers heard about vaccination_Ummbada locality _Albugaa 2017 $\mathrm{n}=384$

Table 1. Sample distribution techniques

\begin{tabular}{|c|c|c|c|c|}
\hline S.no & Study area & $\begin{array}{c}\text { Population } \\
\text { number }\end{array}$ & Sample size & \% \\
\hline 1 & Algoads & 8500 & 52 & 13 \\
\hline 2 & Alhikma 10 & 7920 & 49 & 13 \\
\hline 3 & Albohira & 6900 & 42 & 12 \\
\hline 4 & Alsariha & 13856 & 85 & 22 \\
\hline 5 & Alrahma & 10400 & 64 & 17 \\
\hline 6 & Alryanalhocomi & 14956 & 92 & 24 \\
\hline Total & & 62532 & 384 & 100 \\
\hline
\end{tabular}

increasing immunity of child $(55 \%)$ this reflect role of media in the increase the knowledge see in Figure 4, this result similarly to report by Angelliloin 2003 in Nigeria who stated that majority (75\%) of mothers had high knowledge about vaccination importance.

The result revealed $40 \%$ from mothers had good knowledge about vaccine preventive diseases see in Table 2 , this result similar with study which done in Dar elsalam by Khalda Osman in 2013 proved that $52 \%$ of mothers had good knowledge about vaccine preventive diseases.

The result shown that the majority of mothers (90\%) their children have vaccination card see in Figure 5, this result agree with the slaying of director of vaccination at Ministry of Health of Khartoum state in important of vaccination card.

The result shown that more than half of mothers (52\%) had poor knowledge about number of the routine doses which given to the child less than two years see in Figure 6, this refer to their care less about vaccination card or loss of it.

The result shown that more than half of mothers $(66 \%)$ had positive attitudes toward Completion of all doses of vaccination children is not necessary see in Figure 7, this result similar to study done in Addis
Ababa by Edrees Ali in 2011 which revealed that $62 \%$ of mothers agree with important of completion of compulsory doses of vaccination.

The result show that of mothers (40\%) of mothers negative attitudes toward baby can be left without vaccination and no problem, see in Table 4, this result agree with study done in Egypt by Ahmed in 2005 which shown $73 \%$ of mothers agree that child without vaccination can expose to childhood diseases.

The result shown that good practice of mothers toward vaccination $67 \%$ of mothers go with their child for vaccination at specified time, see in Table 5, this result similar to study done by Shamila Hamid in North

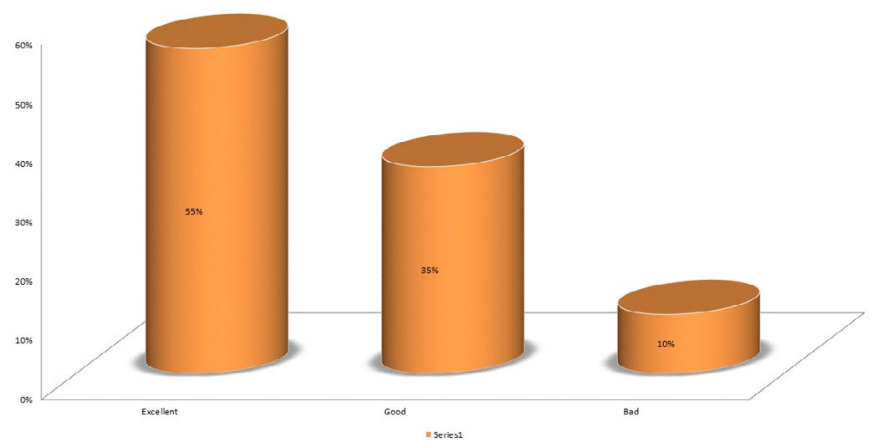

Figure 4. Show the mothers knowledge about importance of vaccination_ Ummbada locality_Albugaa $2017 \mathrm{n}=347$

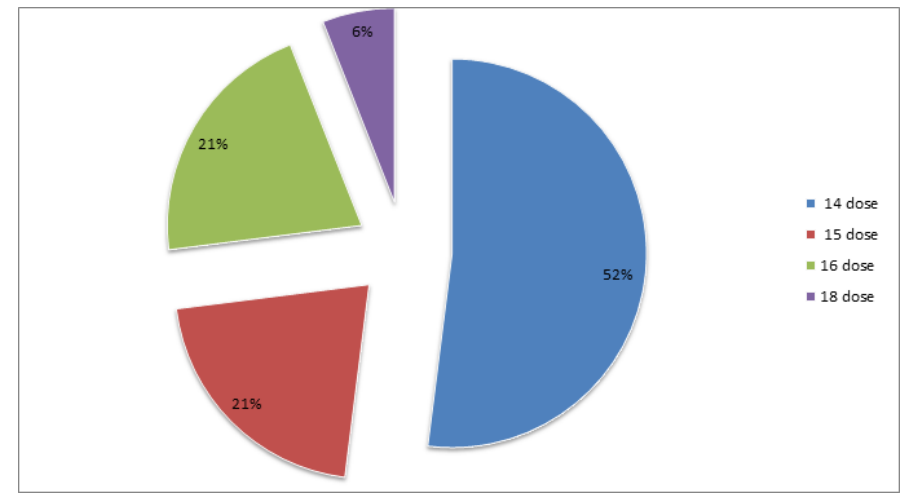

Figure 5. Show the mothers knowledge about number of the routine dose _ Ummbada locality_Albugaa_2017

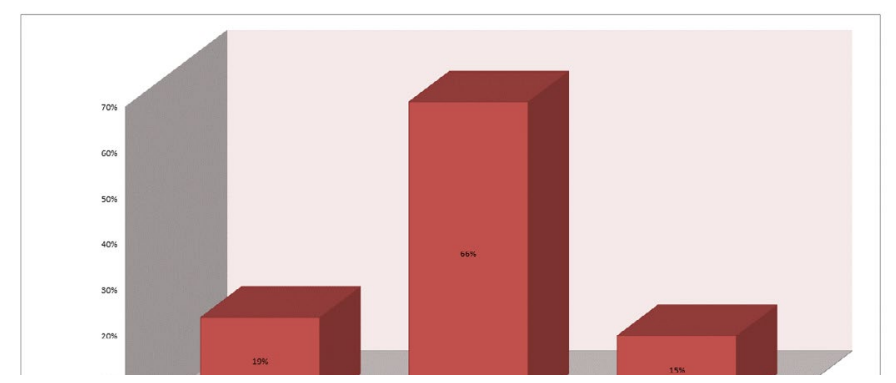

Figure 6. Show the mothers attitude toward Completion of all doses _ Ummbada locality Albugaa_ 2017

Table 2. Show the Family income-Ummbada locality-Albugaa 2017 n=384

\begin{tabular}{|c|c|c|}
\hline Family income & No & \% \\
\hline A_500_1000s & 149 & 39 \\
\hline B_1000_1500 & 132 & 34 \\
\hline C_more than 1500 & 103 & 27 \\
\hline Total & 384 & 100 \\
\hline
\end{tabular}


Kashmir in 2011 about immunization of children, the study revealed that all the mothers (100\%) had good practice toward immunization.

The result shown $62 \%$ of mothers had good practice toward mother carry the child to the health center see in Figure 8, refer to their cared about vaccination and the existence of mother during child immunization for receiving of health instructions which provided in health centers about immunization.

The result revealed that $55 \%$ of mothers had bad practice toward they forgotten and loss of vaccination card, see in Figure 9, this result similar to study done in Almygoma health center by BatulHassan in 2013 which stated that $47 \%$ of mothers loss vaccination cards of their children.

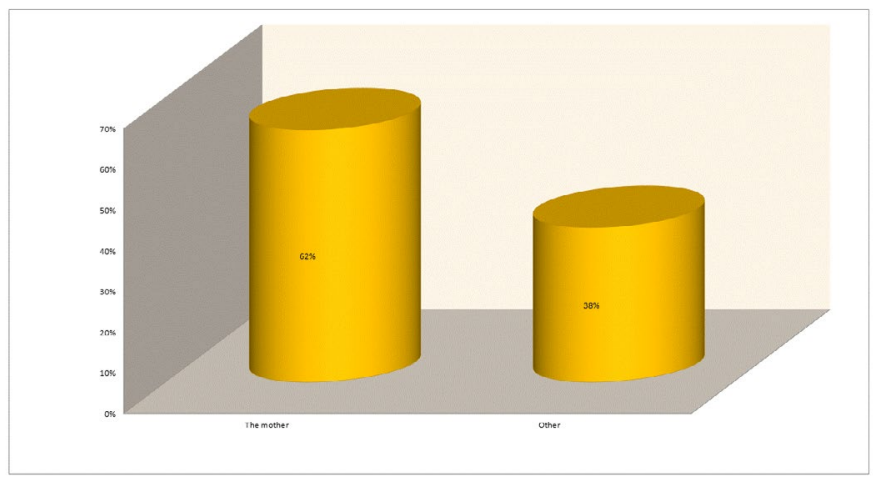

Figure 7. Show the mothers practice toward who is carry the child to the health center Ummbada locality_Albugaa_2017
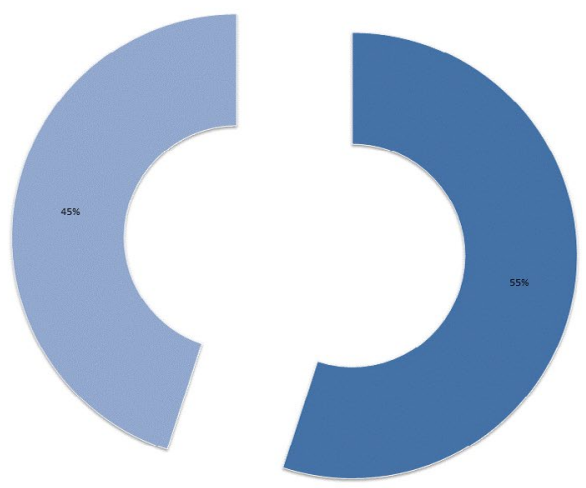

Figure 8. Show mothers practice toward forgotten the vaccination card or lost _ Ummbada locality _Albugaa $2017 \mathrm{n}=347$

Table 3. Show the mother's knowledge of vaccine preventive diseases-Ummbada localityAlbugaa $2017 \mathrm{n}=347$

\begin{tabular}{|c|c|c|}
\hline Degree of knowledge & No & \% \\
\hline Excellent & 93 & 27 \\
\hline Good & 140 & 40 \\
\hline Weak & 114 & 33 \\
\hline Total & 347 & 100 \\
\hline
\end{tabular}

Table 4. Show the mothers knowledge about important of vaccination card-Ummbada locality-Albugaa- $2017 \mathrm{n}=312$

\begin{tabular}{|c|c|c|}
\hline Degree of mothers knowledge & No & \% \\
\hline Excellent & 105 & 34 \\
\hline Good & 72 & 23 \\
\hline Weak & 135 & 43 \\
\hline Total & 312 & 100 \\
\hline
\end{tabular}

Table 5. Show the mothers attitude toward baby left without vaccination-Ummbada locality-Albugaa- $2017 \mathrm{n}=347$

\begin{tabular}{|c|c|c|}
\hline The mothers attitude & No & $\mathbf{\%}$ \\
\hline Agree & 51 & 15 \\
\hline Disagree & 208 & 60 \\
\hline I don't know & 88 & 25 \\
\hline Total & 347 & 100 \\
\hline
\end{tabular}

Table 6. Show the mothers practice toward vaccination at specified time-Ummbada locality-Albugaa-2017 $\mathrm{n}=347$

\begin{tabular}{|c|c|c|}
\hline The mothers practice & No & $\mathbf{\%}$ \\
\hline Yes & 232 & 67 \\
\hline No & 115 & 33 \\
\hline Total & 347 & 100 \\
\hline
\end{tabular}

\section{Conclusion}

The descriptive cross-sectional study conducted among mothers with children years in Ummbada locality (albugaa) to study on knowledge, attitude and practice of mothers toward vaccination of children under five years.

\section{References}

1. Batul HM (2013) Assessment of mother's knowledge and expectation regarding child vaccination. Sudan- University of Bahri- College of Nursing.

2. Park (2013) Preventive and Social Medicine 22 (edn). 138, 144, 151, 154, 156, and 283.

3. World Health Organization (2012) Global Vaccine Action Plan 2011-2020.

4. World Health Organization. (2003). State of the World's Vaccines and Immunization.

5. WHO (2005) Global immunization vision and strategy 2006-2015.

6. WHO (2016) World Immunization Week.

Copyright: (O2019 Fad KH. This is an open-access article distributed under the terms of the Creative Commons Attribution License, which permits unrestricted use, distribution, and reproduction in any medium, provided the original author and source are credited. 